\title{
Impact assessment of land cover changes on the runoff changes on the extreme flood events in the Kelantan River basin
}

\begin{abstract}
In the current years, changing the land cover/land use had serious hydrological impacts affecting the flood events in the Kelantan River basin. The flood events at the east coast of the peninsular Malaysia got highly affected in the recent decades due to several factors like urbanisation, rapid changes in the utilisation of land and lack of meteorological (i.e. change in climate) and developmental monitoring and planning. The Kelantan River basin has been highly influenced due to a rapid change in land use during 1984 to 2013, which occurred in the form of transformation of agricultural area and deforestation (logging activities). In order to evaluate the influence of the modifications in land cover on the flood events, two hydrological regional models of rainfall-induced runoff event, the Hydrologic Engineering Center (HEC)-Hydrologic Modeling System (HMS) model and improved transient rainfall infiltration and grid-based regional model (Improved TRIGRS), were employed in this study. The responses of land cover changes on the peak flow and runoff volume were investigated using 10 days of hourly rainfall events from 20 December to the end of December 2014 at the study area. The usage of two hydrological models defined that the changes in land use/land cover caused momentous changes in hydrological response towards water flow. The outcomes also revealed that the increase of severe water flow at the study area is a function of urbanisation and deforestation, particularly in the conversion of the forest area to the less canopy coverage, for example, oil palm, mixed agriculture and rubber. The monsoon season floods and runoff escalate in the cleared land or low-density vegetation area, while the normal flow gets the contribution from interflow generated from secondary jungle and forested areas.
\end{abstract}

Keyword: Flood event; HEC-HMS model; Improved TRIGRS model; Kelantan River basin; Land cover changes 